\title{
Difference in Chemotype Composition of Fusarium graminearum Populations Isolated from Durum Wheat in Adjacent Areas Separated by the Apennines in Northern-Central Italy
}

\author{
A. Prodi ${ }^{1 *}$,W. Purahong ${ }^{1,2}$, S. Tonti ${ }^{1,3}$, D. Salomoni ${ }^{4}$, P. Nipoti ${ }^{1}$, L. Covarelli ${ }^{5}$ and A. Pisi ${ }^{1}$ \\ ${ }^{1}$ Dipartimento di Scienze e Tecnologie Agroambientali, Alma Mater Studiorum Università di Bologna, via Fanin 40, 40127 \\ Bologna, Italy \\ ${ }^{2}$ Faculty of Agriculture and Life Science, Chandrakasem Rajabhat University, 10900 Bangkok, Thailand \\ ${ }^{3}$ INRAN (ex ENSE-Sezione di Verona), via Ca' Nova Zampieri 37, 37057 San Giovanni Lupatoto, Verona, Italy \\ ${ }^{4}$ Dipartimento di Protezione e Valorizzazione Agroalimentare, Viale Fanin 46, 40127 Bologna, Italy \\ ${ }^{5}$ Dipartimento di Scienze Agrarie e Ambientali, Università degli Studi di Perugia, Borgo XX Giugno, 74, 06121 Perugia, Italy \\ (Received on June 24, 2011; Revised on October 13, 2011; Accepted on October 16, 2011)
}

\begin{abstract}
Chemotype composition of Fusarium graminearum strains, isolated from durum wheat kernels from naturally FHB infected fields in Northern and Central Italy, was investigated by multiplex PCR. The different climatic and environmental conditions of the two examined areas separated by the Apennines affected the composition of chemotypes. 15Ac-DON chemotype was predominant in both the sub areas. Nivalneol chemotype was more frequent in the warmer sub area.
\end{abstract}

Keywords : chemotype, durum wheat, Fusarium graminearum, Fusarium head blight

Fusarium graminearum (teleomorph Gibberella zeae (Schwein.) Petch.) is the major pathogen responsible of Fusarium head blight (FHB), an economically crucial and complex etiology disease on cereal crops worldwide (Goswami and Kistler, 2004). FHB has received more attention because of its effect on yield (Parry et al., 1995), grain quality (Liggitt et al., 1997) and grain contamination by mycotoxins (Visconti et al., 2000). FHB resistant cultivars are considered one of the solutions for the problem related to mycotoxin contamination in wheat grains (Lemmens et al., 2004), but unfortunately to date no resistant cultivar is commercially available for durum wheat. Most attention in the analysis of grain affected by FHB was placed on contamination by deoxynivalenol (DON), acetylated forms of DON (3Ac-DON and 15Ac-DON) and nivalenol (NIV).

DON is a mycotoxin that disturbs and/or inhibits DNA, RNA and protein synthesis by binding to the ribosomal peptidyltransferase site leading to a decrease of cell pro-

\footnotetext{
*Corresponding author.

Phone) +39-051-2096722, FAX) +39-051-2096720

E-mail) antonio.prodi@unibo.it
}

liferation (Shifrin and Anderson, 1999). It is also known as vomitoxin and it is responsible for hemorrhagic and anorexic syndromes, neurotoxic and immunotoxic effects in mammals (Visconti et al., 2004). DON contamination levels in food and feed were found to be much higher than those observed for NIV (Boutigny et al., 2011), being probably the most negligible toxin due to the small amount usually detected (Yazar and Omurtag, 2008), but with consistent levels in many Asian countries, New Zealand and Brazil (Placinta et al., 1999). However, NIV has shown to have a higher toxicity than DON, for example, in human blood cells (Minervini et al., 2004). This toxin has also shown higher activity than DON in inhibiting DNA, and it may account for various toxic phenomena such as induction of cell death (Poapolathep et al., 2002).

Based on the production of type B trichothecenes, DON and NIV, three F. graminearum chemotypes have been described: 3Ac-DON, 15Ac-DON and NIV. Chemotype identification is broadly used to characterize $F$. graminearum for its toxigenic potential (Pasquali et al., 2009). There was a correlation between the presence of $F$. graminearum chemotype and wheat grain mycotoxin content. DON and NIV contents can be successfully predicted by quantifying the fungal biomass of DON and NIV producers with a realtime PCR quantification method (Brandfass and Karlovsky, 2006; Burlakoti et al., 2007; Pasquali et al., 2009).

The dominant chemotypes of $F$. graminearum vary within geographical areas, i.e. different countries and/or continents (Prodi et al., 2009b), but some host preference may affect the composition of chemotypes of F. graminearum population. Within the same country, the different geographical areas (i.e. plain, mountains, valleys, etc.) and distances from the sea, may also affect the composition of chemotypes of a fungal population. Mountains may play an importance role as natural obstacles by inhibiting the 
diffusion of $F$. graminearum to other areas and preventing the genetic exchange among populations. The sea may provide humidity and enhance the suitable conditions for $F$. graminearum infection. Different locations have different environmental and climatic conditions, therefore also $F$. graminearum populations should be adapted to the environment under the pressure of natural selection.

The aim of this study was to investigate the chemotype differences of $F$. graminearum populations identified from different regions of Northern-Central Italy, separated by the Apennine mountains.

Durum wheat kernels from different cultivars were collected from naturally FHB infected fields within three
Italian regions (Emilia Romagna, The Marche and Umbria) of Northern-Central Italy during the years 2009-2010 (Table 1). Emilia-Romagna and The Marche are separated from Umbria by the Apennines (Fig. 1) and, therefore, we considered two sub areas: Emilia-Romagna and The Marche merged in the sub area 1 and Umbria in sub area 2. Four hundreds kernels from each of 63 samples of wheat collected were washed in sterile water, disinfected in a $2 \%$ sodium hypochlorite solution for $2 \mathrm{~min}$, then placed in Petri dishes containing potato dextrose agar (Difco, USA) with $0.3 \mathrm{~g} \mathrm{~L}^{-1}$ streptomycin and neomycin sulphate. The Petri dishes were incubated at $22^{\circ} \mathrm{C}$ in the dark for seven days (Pancaldi et al., 2010). F. graminearum was identified, from

Table 1. Chemotypes of $F$. graminearum isolated in the three different examined regions

\begin{tabular}{|c|c|c|c|c|}
\hline No. isolates & Field localities & Regions & Cultivars & Chemotypes \\
\hline \multicolumn{5}{|c|}{ Sub area 1} \\
\hline ER 1 & Baricella & Emilia Romagna & Neolatino & NIV \\
\hline ER 2 & Baricella & Emilia Romagna & Normanno & $15 \mathrm{Ac}-\mathrm{DON}$ \\
\hline ER 3 & Budrio & Emilia Romagna & Iride & $15 \mathrm{Ac}-\mathrm{DON}$ \\
\hline ER 4 & Busseto & Emilia Romagna & PR22D89 & $15 \mathrm{Ac}-\mathrm{DON}$ \\
\hline ER 5 & Cadriano & Emilia-Romagna & Bologna & $15 \mathrm{Ac}-\mathrm{DON}$ \\
\hline ER 6 & Conselice & Emilia-Romagna & Tiziana & $15 \mathrm{Ac}-\mathrm{DON}$ \\
\hline ER 7 & Crespellano & Emilia Romagna & Normanno & $15 \mathrm{Ac}-\mathrm{DON}$ \\
\hline ER 8 & Crevalcore & Emilia Romagna & Dupri & $15 \mathrm{Ac}-\mathrm{DON}$ \\
\hline ER 9 & Faenza & Emilia-Romagna & Saragolla & $15 \mathrm{Ac}-\mathrm{DON}$ \\
\hline ER 10 & Ferrara & Emilia-Romagna & PR22D66 & $15 \mathrm{Ac}-\mathrm{DON}$ \\
\hline ER 11 & Ferrara & Emilia Romagna & Levante & $15 \mathrm{Ac}-\mathrm{DON}$ \\
\hline ER 12 & Fiorenzuola d'Arda & Emilia-Romagna & Simeto & $15 \mathrm{Ac}-\mathrm{DON}$ \\
\hline ER 13 & Malalbergo & Emilia Romagna & Saragolla & NIV \\
\hline ER 14 & Mezzolara & Emilia Romagna & Iride & $15 \mathrm{Ac}-\mathrm{DON}$ \\
\hline ER 15 & Molinella & Emilia Romagna & Normanno & $15 \mathrm{Ac}-\mathrm{DON}$ \\
\hline ER 16 & Molinella & Emilia-Romagna & Saragolla & $15 \mathrm{Ac}-\mathrm{DON}$ \\
\hline ER 17 & Noceto & Emilia Romagna & 22D78/874928 & $15 \mathrm{Ac}-\mathrm{DON}$ \\
\hline ER 18 & Noceto & Emilia-Romagna & 22D89/875015 & $15 \mathrm{Ac}-\mathrm{DON}$ \\
\hline ER 19 & Noceto & Emilia-Romagna & 22D40/875011 & $15 \mathrm{Ac}-\mathrm{DON}$ \\
\hline ER 20 & Ostellato & Emilia-Romagna & Hathor & $15 \mathrm{Ac}-\mathrm{DON}$ \\
\hline ER 21 & Parma & Emilia Romagna & Simeto & 3Ac-DON \\
\hline ER 22 & Ravenna & Emilia-Romagna & Saragolla & $15 \mathrm{Ac}-\mathrm{DON}$ \\
\hline ER 23 & Ravenna & Emilia-Romagna & Orobel & $15 \mathrm{Ac}-\mathrm{DON}$ \\
\hline ER 24 & Ravenna & Emilia Romagna & S. Carlo & $15 \mathrm{Ac}-\mathrm{DON}$ \\
\hline ER 25 & S. Agostino & Emilia-Romagna & Svevo & $15 \mathrm{Ac}-\mathrm{DON}$ \\
\hline ER 26 & S. Giorgio di Piano & Emilia Romagna & Neolatino & 3Ac-DON \\
\hline ER 27 & S. Pietro Capofiume & Emilia Romagna & S.Carlo & 3Ac-DON \\
\hline ER 28 & S. Pietro in Casale & Emilia-Romagna & Alcione & $15 \mathrm{Ac}-\mathrm{DON}$ \\
\hline ER 29 & Selva Malvezzi & Emilia Romagna & Anco Marzio & $15 \mathrm{Ac}-\mathrm{DON}$ \\
\hline ER 30 & Copparo & Emilia-Romagna & Iride & $15 \mathrm{Ac}-\mathrm{DON}$ \\
\hline ER 31 & Copparo & Emilia-Romagna & Iride & $15 \mathrm{Ac}-\mathrm{DON}$ \\
\hline ER 32 & Tamara & Emilia-Romagna & Iride & $15 \mathrm{Ac}-\mathrm{DON}$ \\
\hline ER 33 & Tamara & Emilia-Romagna & Iride & $15 \mathrm{Ac}-\mathrm{DON}$ \\
\hline
\end{tabular}


Table 1. Continued

\begin{tabular}{|c|c|c|c|c|}
\hline No. isolates & Field localities & Regions & Cultivars & Chemotypes \\
\hline \multicolumn{5}{|c|}{ Sub area 1} \\
\hline M 1 & Ancona & The Marche & Saragolla & $15 \mathrm{Ac}-\mathrm{DON}$ \\
\hline M 2 & Ancona & The Marche & Rusticano & $15 \mathrm{Ac}-\mathrm{DON}$ \\
\hline M 4 & Castelfidardo & The Marche & Claudio & $15 \mathrm{Ac}-\mathrm{DON}$ \\
\hline M 5 & Jesi & The Marche & Liberdur & $15 \mathrm{Ac}-\mathrm{DON}$ \\
\hline M 6 & Jesi & The Marche & Svevo & $15 \mathrm{Ac}-\mathrm{DON}$ \\
\hline M 7 & Jesi & The Marche & San Carlo & $15 \mathrm{Ac}-\mathrm{DON}$ \\
\hline M 8 & Jesi & The Marche & Ancomarzio & $15 \mathrm{Ac}-\mathrm{DON}$ \\
\hline M 9 & Jesi & The Marche & Flaminio & $15 \mathrm{Ac}-\mathrm{DON}$ \\
\hline M 10 & Jesi & The Marche & Levante & $15 \mathrm{Ac}-\mathrm{DON}$ \\
\hline M 11 & Jesi & The Marche & Saragolla & $15 \mathrm{Ac}-\mathrm{DON}$ \\
\hline M 12 & Jesi & The Marche & Normanno & 3Ac-DON \\
\hline M 13 & Jesi & The Marche & Colosseo & $15 \mathrm{Ac}-\mathrm{DON}$ \\
\hline M 14 & Jesi & The Marche & Colosseo & NIV \\
\hline M 15 & Jesi & The Marche & Dylan & $15 \mathrm{Ac}-\mathrm{DON}$ \\
\hline M 16 & Jesi & The Marche & Ciccio & $15 \mathrm{Ac}-\mathrm{DON}$ \\
\hline M 17 & Macerata & The Marche & S.Carlo & $15 \mathrm{Ac}-\mathrm{DON}$ \\
\hline M 18 & Montefano & The Marche & Achille & $15 \mathrm{Ac}-\mathrm{DON}$ \\
\hline M 19 & Montefano & The Marche & San Carlo & NIV \\
\hline M 20 & San Severino Marche & The Marche & San Carlo & $15 \mathrm{Ac}-\mathrm{DON}$ \\
\hline M 21 & Treia & The Marche & Dorato & $15 \mathrm{Ac}-\mathrm{DON}$ \\
\hline \multicolumn{5}{|c|}{ Sub area 2} \\
\hline U 1 & Perugia & Umbria & Avispa & $15 \mathrm{Ac}-\mathrm{DON}$ \\
\hline $\mathrm{U} 2$ & Perugia & Umbria & Saragolla & $15 \mathrm{Ac}-\mathrm{DON}$ \\
\hline U 3 & Perugia & Umbria & Grecale & $15 \mathrm{Ac}-\mathrm{DON}$ \\
\hline U 4 & Perugia & Umbria & Avispa & NIV \\
\hline U 5 & Acquasparta & Umbria & Iride & NIV \\
\hline U 6 & Capanne & Umbria & Unknown & NIV \\
\hline U 7 & Casalina & Umbria & Latinur & $15 \mathrm{Ac}-\mathrm{DON}$ \\
\hline U 8 & Casalina & Umbria & Latinur & 3Ac-DON \\
\hline U 9 & Casalina & Umbria & Latinur & $3 \mathrm{Ac}-\mathrm{DON}$ \\
\hline U 10 & Clitunno & Umbria & Grecale & $15 \mathrm{Ac}-\mathrm{DON}$ \\
\hline U 11 & Colombella & Umbria & Avispa & $15 \mathrm{Ac}-\mathrm{DON}$ \\
\hline U 12 & Corciano & Umbria & Claudio & $15 \mathrm{Ac}-\mathrm{DON}$ \\
\hline U 13 & Foligno & Umbria & Sorrento & $15 \mathrm{Ac}-\mathrm{DON}$ \\
\hline U 14 & Spello & Umbria & Unknown & NIV \\
\hline U 15 & Magione & Umbria & Unknown & NIV \\
\hline U 16 & Marsciano & Umbria & Unknown & $15 \mathrm{Ac}-\mathrm{DON}$ \\
\hline U 17 & Panicarola & Umbria & Ermocolle & NIV \\
\hline U 18 & Castiglioni del lago & Umbria & Unknown & $15 \mathrm{Ac}-\mathrm{DON}$ \\
\hline U 19 & Pozzuolo & Umbria & Duilio & $15 \mathrm{Ac}-\mathrm{DON}$ \\
\hline $\mathrm{U} 20$ & S. Fatucchio & Umbria & Latinur & NIV \\
\hline U 21 & Marsciano & Umbria & Saragolla & $15 \mathrm{Ac}-\mathrm{DON}$ \\
\hline $\mathrm{U} 22$ & Pozzuolo & Umbria & Quadrato & $3 \mathrm{Ac}-\mathrm{DON}$ \\
\hline
\end{tabular}

the single spore cultures obtained, according to morphological criteria described by Leslie and Summerell (2006). DNA from $75 F$. graminearum strains, morphologically identified, was extracted using a CTAB method (Suarez et al., 2005), modified in this work using seven days fungal mycelium (100-200 mg) and adding $1 \mu \mathrm{l}$ of proteinase $\mathrm{K}$ 


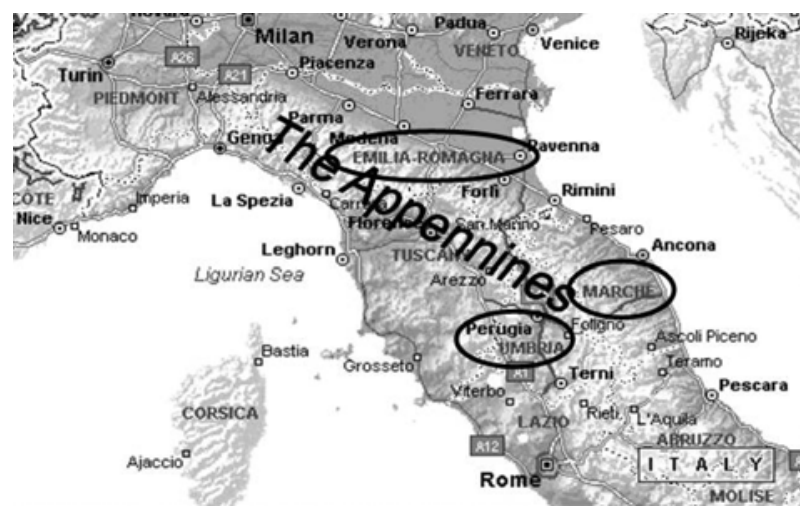

Fig. 1. Map of Northern-Central Italy, indicating the two sub areas studied (Sub area 1: Emila-Romagna and The Marche; sub area 2: Umbria).

( $20 \mathrm{mg} / \mathrm{ml}$ ) to CTAB-grinding buffer shortly before the use. $F$. graminearum DNA was analyzed with specific primers Fg16F/Fg16R under the conditions described by Nicholson et al. (1998), to determine the identity of all the strains.

$F$. graminearum was isolated from all the samples, no more than two isolates of $F$. graminearum per sample were chosen, and 75 isolates were used for further studies (Table 1). The molecular results confirmed the microscopic identifications, based on macroconidia characteristics, with the presence of the expected band of $410 \mathrm{bp}$.

The potential capacity of $F$. graminearum isolates to produce trichothecenes was evaluated using a multiplex PCR version (Starkey et al., 2007) as described by Prodi et al. (2009b). Primers, designed in the region of the Tri12 gene located in the terminal gene cluster for trichothecene biosynthesis, can distinguish three subgroups depending on the type of $\beta$-trichothecene produced. One primer is common to all chemotypes (12CON) and the others are chemotype-specific for 15Ac-DON (12-15F), 3Ac-DON (12-3F) and NIV (12NF) (Starkey et al., 2007).

All three chemotypes were found in both sub areas at each side of the Apennines (Table 1) and verified with the presence of the expected band of $670 \mathrm{bp}$ for 15Ac-DON chemotype, of $410 \mathrm{bp}$ for $3 \mathrm{Ac}-\mathrm{DON}$ and of $840 \mathrm{bp}$ for NIV. Sixty-four strains were found to be DON producers (57 strains $15 \mathrm{Ac}-\mathrm{DON}$ and $73 \mathrm{Ac}-\mathrm{DON})$. Eleven strains showed to be NIV chemotype. Although in both areas the 15AcDON chemotype was dominant, the percentage of $15 \mathrm{Ac}$ DON was variable. In Emilia Romagna and The Marche (sub area 1), the 15Ac-DON chemotype was accounting to $84 \%$ followed by 3 Ac-DON and NIV at $8 \%$ (Fig. 2). In Umbria (sub area 2) 15 Ac-DON chemotype was accounting to $54 \%$. NIV was accounting to $32 \%$ and $3 A c-D O N$ to $14 \%$ (Fig. 2).

This study is consistent with previous studies and reveals that $F$. graminearum 15Ac-DON chemotype is prevalent in
(A) Sub area 1

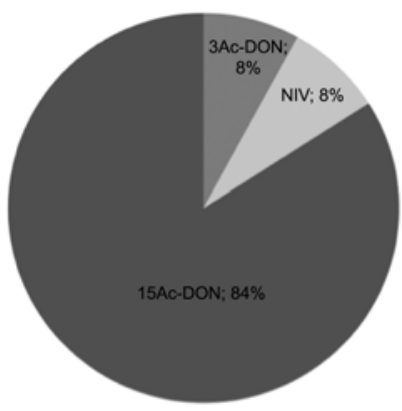

(B) Sub area 2

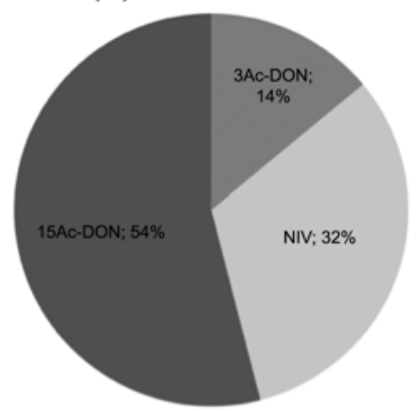

Fig. 2. Frequency of the three $F$. graminearum chemotypes in sub area 1 (A) and sub area 2 (B).

Italy, while $3 \mathrm{Ac}-\mathrm{DON}$ and NIV chemotypes are much less frequently detected (Gale et al., 2007; Prodi et al., 2009a). Prodi et al. (2009b) found only two isolates of NIV from a total of 74 isolates of $F$. graminearum in 43 fields of a restricted area of Emilia Romagna.

This is the first study that provides data suggesting a different chemotype composition of $F$. graminearum within two adjacent geographical areas separated by natural obstacles. Emilia Romagna and The Marche are separated from Umbria by the Apennine mountains and their climate is classified as humid subtropical while Umbria has a Mediterranean climate (Peel et al., 2007). Humid subtropical climate is characterized by cold winters with average temperatures around $0 / 1{ }^{\circ} \mathrm{C}$ (winters usually colder than those of some countries at higher latitudes), hot summers (average temperature $22 / 24^{\circ} \mathrm{C}$ ), high precipitations and absence of a dry season. Mediterranean climate has hot and dry summer, mild winter and rainy autumn. In Umbria, the Apennines act as a barrier to the influence of the Adriatic sea and to the North-east cold air but, several changes in altitude and geographical position can generate a huge variety of climates. The geographical differences in the two sub areas create a specific different climate and environment that may affect the fitness of some chemotypes (Ward et al., 2002). Jennings et al. (2004) proposed that environmental favorable conditions explain the distribution of $F$. culmorum chemotypes in different geographical areas. We suppose that this hypothesis may also be valid in the case of F. graminearum. In China, Zhang et al. (2007) reported how temperature affects the different distribution of $F$. graminearum chemotypes and they showed that DON producers were present in cooler regions with the annual average temperatures of $15^{\circ} \mathrm{C}$ or lower. On the other hand, NIV chemotype and the new subpopulation of $15 \mathrm{Ac}-\mathrm{DON}$ producers are mostly present in warmer regions where the annual average temperatures are above $15^{\circ} \mathrm{C}$. This finding somehow supports our results on the different chemotype composition between the two sub areas located on different 
sides of the Apennines. In the warmer region with Mediterranean climate (Umbria) $F$. graminearum NIV producers are present three fold more than in cooler regions (Emilia Romagna and The Marche) where we observed a high percentage of DON producers (total 92\%; 15Ac-DON= $84 \%$ and $3 \mathrm{Ac}-\mathrm{DON}=8 \%$ ).

However, our results do not show a clear cut like reported by Zhang et al. (2007). In Umbria, the warmest region, the percentage of DON producers was still high (total $68 \%$; $54 \%$ for $15 \mathrm{Ac}-\mathrm{DON}$ and $14 \% 3 \mathrm{Ac}-\mathrm{DON})$. In our experiment this could be explained with two hypothesis: first, $F$. graminearum NIV chemotype, mentioned by Zhang et al. (2007), is in lineage 6, so in some way they may behave differently from $F$. graminearum population of NorthernCentral Italy (lineage 7 ), exclusively isolated from durum wheat. On rice Lee et al. (2009), observed that the different ecological ability between lineage 6 isolates and lineage 7 isolates were not directly related to the mechanism of pathogenicity; second, it is possible that some chemotypes of $F$. graminearum could be transported to other locations by seed shipping and long-distance spore transportation influencing chemotype composition (Guo et al., 2008). In fact in Western Canada, between 1998 and 2004, it was detected an increase of more than 14-fold of F. graminearum 3Ac-DON producers: that was linked to an introduction of a $3 \mathrm{Ac}-\mathrm{DON}$ pathogenic population that was more toxigenic and vigorous, with a selective advantage above 15Ac-DON chemotype (Ward et al., 2008).

We can conclude that the different climatic and environmental conditions of the two examined areas separated by the Apennines affected the chemotypes composition of $F$. graminearum. 15Ac-DON was predominant in both the sub areas while NIV chemotype was more frequently detected in Umbria, the warmest sub area.

\section{Acknowledgments}

We wish to thank Dr. M. Montanari and Dr. A. Sommovigo (INRAN - ex ENSE sect. Bologna) for kindly supplying several grain samples and Dr. I. Alberti (INRAN - ex ENSE sect. Verona) for her scientific advice. The work was supported by Agenzia Servizi Settore Agroalimentare delle Marche (ASSAM) with the Project "Studi di carattere epidemiologico, monitoraggi e lotta ad alcune malattie fungine delle colture agrarie della Regione Marche". Witoon Purahong was founded by an Erasmus Mundus Scholarship (IMaHS) from the University of Bologna.

\section{References}

Boutigny, A. L., Ward, T. J., Van Coller, G. J., Flett, B., Lamprecht, S. C., O'Donnell, K. and Viljoen, A. 2011. Analysis of the
Fusarium graminearum species complex from wheat, barley and maize in South Africa provides evidence of species-specific differences in host preferences. Fungal Genet. Biol. 48: 914-920.

Brandfass, C. and Karlovsky, P. 2006. Simultaneous detection of Fusarium culmorum and $F$. graminearum in plant material by duplex PCR with melting curve analysis. BMC Microbiol. 6: 4.

Burlakoti, R. R., Estrada, Jr. R., Rivera, V. V., Boddeda, A., Secor, G. A. and Adhikari, T. B. 2007. Real-time PCR quantification and mycotoxin production of Fusarium graminearum in wheat inoculated with isolates collected from potato, sugar beet and wheat. Phytopathology 97:835-841.

Gale, L. R., Ward, T. J., Balmas, V. and Kistler, H. C. 2007. Population subdivision of Fusarium graminearum sensu stricto in the upper Midwestern United States. Phytopathology 97: 1434-1439.

Goswami, R. S. and Kistler, H. C. 2004. Heading for disaster: Fusarium graminearum on cereal crops. Mol. Plant Pathol. 5: $515-525$.

Guo, X. W., Fernando, W. G. D. and Seow-Brock, H. Y. 2008. Population structure, chemotype diversity, and potential chemotype shifting of Fusarium graminearum in wheat fields of Manitoba. Plant Dis. 92:756-762.

Jennings, P., Coates, M. E., Turner, J. A., Chandler, E. A. and Nicholson, P. 2004. Determination of deoxynivalenol and nivalenol chemotypes of Fusarium culmorum isolates from England and Wales by PCR assay. Plant Pathol. 53:182-190.

Lee, J., Chang, I. Y., Kim, H., Yun, S. H., Leslie, J. F. and Lee, Y. W. 2009. Genetic diversity and fitness of Fusarium graminearum populations from rice in Korea. Appl. Environ. Microbiol. 75:2389-3295.

Lemmens, M., Buerstmayr, H., Krska, R., Schuhmacher, R., Grausgruber, H. and Ruckenbauer, P. 2004. The effect of inoculation treatment and long-term application of moisture on Fusarium head blight symptoms and deoxynivalenol contamination in wheat grains. Eur. J. Plant Pathol. 110:299-308.

Leslie, J. F. and Summerell, B. A. 2006. The Fusarium Laboratory Manual. Blackwell Publishing Professional, Ames, IA, USA.

Liggitt, J., Jenkinson, P. and Parry, D. W. 1997. The role of saprophytic microflora in the development of Fusarium ear blight of winter wheat by Fusarium culmorum. Crop Protect. 16: 679-685.

Minervini, F., Fornelli, F. and Flynn, K. M. 2004. Toxicity and apoptosis induced by the mycotoxins nivalenol, deoxynivalenol and fumonisin B1 in a human erythroleukemia cell line. Toxicol. In vitro 18:21-28.

Nicholson, P., Simpson, D. R., Weston, G., Rezanoor, H. N., Lees, A. K., Parry, D. W. and Joyce, D. 1998. Detection and quantification of Fusarium culmorum and Fusarium graminearum in cereals using PCR assays. Physiol. Mol. Plant Pathol. 53:17-37.

Pancaldi, D., Tonti, S., Prodi, A., Salomoni, D., Dal Prà, M., Nipoti, P., Alberti, I. and Pisi, A. 2010. Survey of the main causal agents of fusarium head blight of durum wheat around Bologna, northern Italy. Phytopathol. Medit. 49:258-266. 
Parry, D. W., Jekinson, P. and Mcleod, L. 1995. Fusarium ear blight (scab) in small grain cereals a review. Plant Pathol. 44: 207-238.

Pasquali, M., Giraud, F., Brochot, C., Cocco, E., Hoffmann, L. and Bohn, T. 2009. Genetic Fusarium chemotyping as a useful tool for predicting nivalenol contamination in winter wheat. Int. J. Food Microbiol. 137:246-253.

Peel, M. C., Finlayson, B. L. and McMahon, T. A. 2007. Updated world map of the Köppen-Geiger climate classification. Hydrol. Earth Syst. Sci. 11:1633-1644.

Placinta, C. M., D’Mello, J. P. F., MacDonald, A. M. C. 1999. A review of worldwide contamination of cereal grains and animal feed with Fusarium mycotoxins. Anim. Feed Sci. Technol. 78:21-37.

Poapolathep, A., Ohtsuka, R., Kiatipattanasakul, W., Ishigami, N., Nakayama, H. and Doi, K. 2002. Nivalenol-induced apoptosis in thymus, spleen and Peyer's patches of mice. Exp. Toxicol. Pathol. 53:441-446.

Prodi, A., Nipoti, P., Bertacchini, E., Tonti, S., Alberti, I., Dal Prà, M., Montanari, M., Pancaldi, D., Covarelli, L., Infantino, A., Santori, A. and Balmas, V. 2009a. Presence of deoxynivalenol and nivalenol chemotypes of Fusarium graminearum isolated from durum wheat in Italy. J. Plant Pathol. 91 (4, Supplement): S4.81.

Prodi, A., Tonti, S., Nipoti, P., Pancaldi, D. and Pisi, A. 2009 b. Identification of deoxynivalenol and nivalenol producing chemotypes of Fusarium graminearum isolates from durum wheat in a restricted area of Northen Italy. J. Plant Pathol. 91:611-615.

Shifrin, V. I. and Anderson, P. 1999. Trichothecene mycotoxins trigger a ribotoxic stress response that activates c-Jun Nterminal kinase and p38 mitogen-activated protein kinase and induces apoptosis. J. Biol. Chem. 274:13985-13992.

Starkey, D. E., Ward, T. J., Aoki, T., Gale, L. R., Kistler, H. C.,
Geiser, D. M., Suga, H., Toth, B., Varga, J. and O'Donnell, K. 2007. Global molecular surveillance reveals novel Fusarium head blight species and trichothecene toxin diversity. Fungal Genet. Biol. 44:1191-1204.

Suarez, M. B., Walsh, K., Boonham, N., O'Neill, T., Pearson, S. and Barker, I. 2005. Development of real-time PCR (Taq$\mathrm{Man}^{\circledR}$ ) assays for the detection and quantification of Botrytis cinerea in planta. Plant Physiol. Biochem. 43:890-899.

Visconti, A., Solfrizzo, M., Avantaggiato, G. and De Girolamo, A. 2000. Strategies for detoxification of Fusarium mycotoxins and assessing in vitro the relevant effectiveness. In: Proceedings of Brighton Crop Protection Conference - Pests and Diseases, pp 721-728.

Visconti, A., Haidukowski, E. M., Pascale, M. and Silvestri, M. 2004. Reduction of deoxynivalenol during durum wheat processing and spaghetti cooking. Toxicol. Lett. 153:181-189.

Ward, T. J., Bielawski, J. P., Kistler, H. C., Sullivan, E. and O'Donnell, K. 2002. Ancestral polymorphism and adaptative evolution in the trichothecene mycotoxin gene cluster of phytopathogenic Fusarium. Proc. Natl. Acad. Sci. USA 99:92789283.

Ward, T. J., Clear, R. M., Rooney, A. P., O’Donnell, K., Gaba, D., Patrick, S., Starkey, D. E., Gilbert, J., Geiser, D. M. and Nowicki, T. W. 2008. An adaptive evolutionary shift in Fusarium head blight pathogen populations is driving the rapid spread of more toxigenic Fusarium graminearum in North America. Fungal Genet. Biol. 45:473-484.

Yazar, S. and Omurtag, G. 2008. Fumonisins, trichothecenes and zearalenone in cereals. Int. J. Mol. Sci. 9:2062-2090.

Zhang, J. B., Li, H. P., Dang, F. J., Qu, B., Xu, Y. B., Zhao, C. S. and Liao, Y. C. 2007. Determination of the trichothecene mycotoxin chemotypes and associated geographical distribution and phylogenetic species of the Fusarium graminearum clade from China. Mycol. Res. 111:967-975. 